öGUM-Mitteilungen

Österreichische Gesellschaft für Ultraschall

\title{
ÖGUM-WEBINARE 2020/2021
}

\section{(킁 ÖGUM Webinare}

Mittwoch, 11.11.2020 18.00 Uhr

Hannes Gruber: Ultraschallgesteuerte Behandlung des Karpaltunnelsyndroms

Mittwoch, 09.12.2020 18.00 Uhr

Philipp Klaritsch: Fetale Auffälligkeiten Fallbesprechungen aus der täglichen Ultraschallpraxis

\section{Mittwoch, 13.01.2021 18.00 Uhr}

Samir Helmy: Fallvorstellungen Gynäkologie

\section{Kosten:}

kostenfrei

DFP: Pro Webinar kann 1 DFP-Punkt erworben werden.

Wir danken Canon Medical für die Unterstützung!

Die Anmeldung erfolgt über die ÖGUM Website (www.oegum.at) oder per E-Mail an geschaeftsstelle@oegum.at.

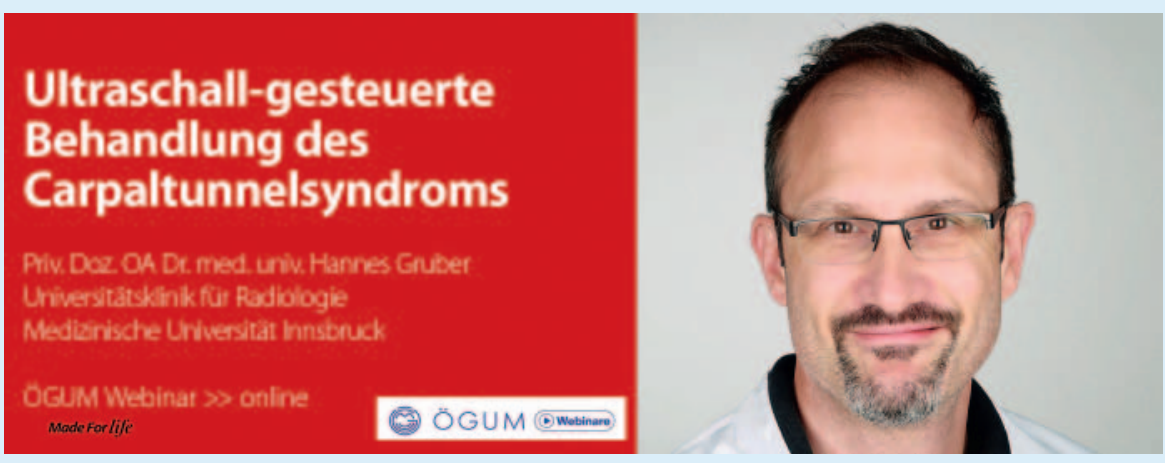

\section{Ultraschall 2021}

\section{6.-8. Oktober 2021 Salzburg Congress}

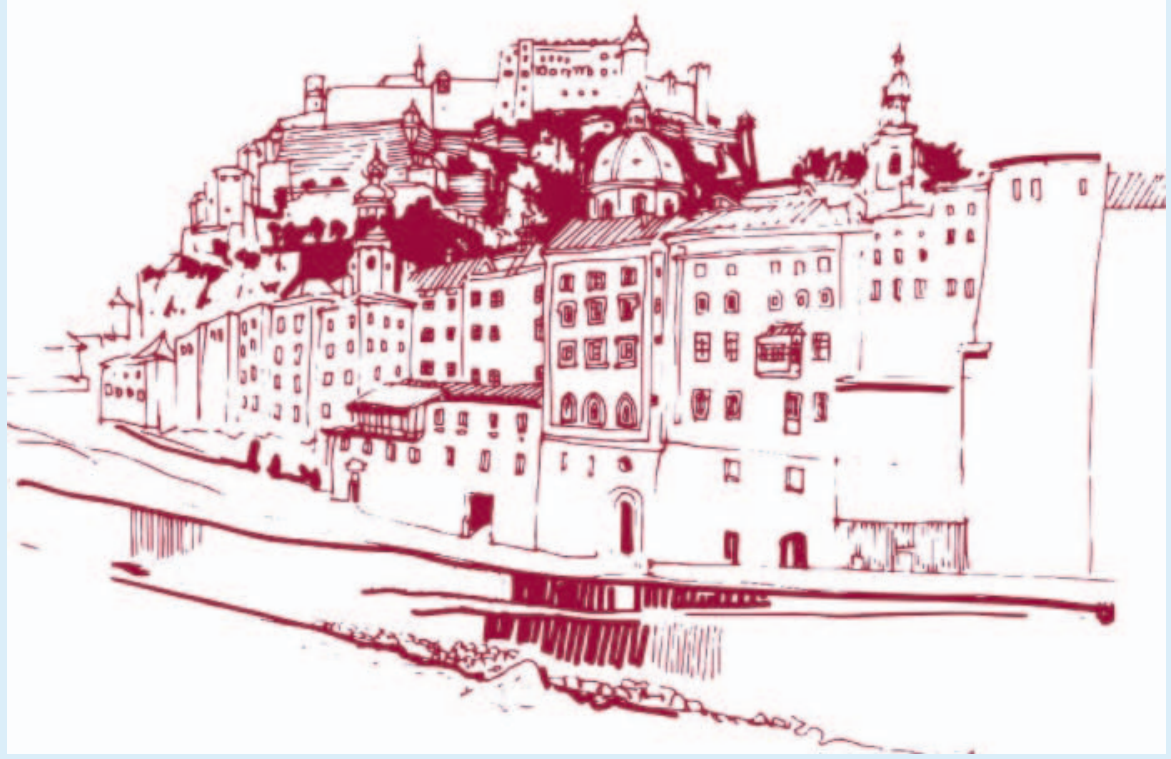

